\title{
OPTIMIZATION OF A NOVEL KINETIC-ASSISTED INFUNDATION FOR RICH-EGCG AND POLYPHENOLS OF WHITE TEA (CAMELLIA SINENSIS) USING CENTRAL COMPOSITE DESIGN
}

\author{
SHAUM SHIYAN ${ }^{1,2}$, TRIANA HERTIANI ${ }^{2}$, RONNY MARTIEN ${ }^{2}$, AKHMAD KHARIS NUGROHO ${ }^{2 *}$
}

1Programme of Pharmacy, Faculty of Mathematic and Natural Sciences, Universitas Sriwijaya, Indralaya, Sumatera Selatan, Indonesia, 2Faculty of Pharmacy, Universitas Gadjah Mada, Sleman, D. I. Yogyakarta, 5281, Indonesia

Email: a.k.nugroho@ugm.ac.id

Received: 09 Sep 2018, Revised and Accepted: 04 Oct 2018

\section{ABSTRACT}

Objective: This research aimed to find modeling and optimization of a novel kinetic-assisted infundation for rich-epigallocatechin gallate (EGCG) and polyphenols extraction from white tea leaf (Camellia sinensis L.).

Methods: The optimal conditions for the best extraction of kinetic-assisted infundation were determined using central composite design. The content of EGCG, catechin, gallic acid, caffeine, theobromine, and theophylline was quantified using high-performance liquid chromatography with ultraviolet detection (HPLC/UV-detection). The total polyphenolic content (TPC) and total flavonoid content (TFC) was measured using the spectrophotometric method. The semi-purified extract was characterized by HPLC, fourier transform infrared spectrophotometry-universal attenuated total reflectance (FTIR-UATR), and powder-X ray diffraction (P-XRD). The extraction mechanism of target compounds was analyzed using scanning electron microscopy (SEM) qualitatively.

Results: The optimum process for the rich-EGCG and polyphenolic extraction using kinetic-assisted infundation was the concentration of simplicia $14.75 \%$, the stir rate $440 \mathrm{rpm}$, and extraction time $12.31 \mathrm{~min}$. The yield of extracts, TPC, TFC, EGCG, caffeine, gallic acid, and theobromine contents in the optimal extraction process were $9.34 \%, 70.97 \%, 13.95 \%, 29.02 \%, 11.95 \%, 1.33 \%$, and $0.33 \%$, respectively.

Conclusion: The kinetic-assisted infundation method proved to be easy to apply with good results as an alternative technique for extracting polyphenolic compounds and rich-EGCG from white tea leaves.

Keywords: White tea, Central composite design, Polyphenols, Kinetic-assisted infundation, Epigallocatechin gallate

(C) 2018 The Authors. Published by Innovare Academic Sciences Pvt Ltd. This is an open access article under the CC BY license (http://creativecommons.org/licenses/by/4.0/) DOI: http://dx.doi.org/10.22159/ijap.2018v10i6.29654

\section{INTRODUCTION}

White tea of Camellia sinensis L. is produced from the youngest part of the leaf (leaf bud). The most common active compounds are polyphenols such as epigallocatechin gallate (EGCG) and other catechin derivatives $[1,2]$. Other ingredients found in white tea are caffeine, theobromine, and theophylline. Epigallocatechin gallate has robust pharmacological activities as an antioxidant agent and oxidative stress inhibitor. White tea contains EGCG reported to have multiple pharmacological effects, such as antidiabetic [3], antiobesity [4], antihypercholesterolemic [4], neuroprotection [5], anticancer and DNA protective [6]. Based on many references, polyphenols have been shown to have extensive pharmacological activities [7-9]. Therefore, it is exciting to develop polyphenol extraction techniques in order to obtain the active compound of quality natural ingredients.

Kinetic-assisted infundation (KAI) is an extraction technique developed from conventional infundation (CIn) methods. Conventional methods have disadvantages such as slow-moving compound transfer processes caused by low solvent penetration [10, 11]. In other conditions, advanced methods such as ultrasoundassisted extraction (UAE) and microwave-assisted extraction (MAE) are not necessarily suitable for the extraction of active compounds from white tea. The supercritical fluid, UAE, and MAE are applied to reduce the use of organic solvents and to shorten the extraction process. However, such methods require high energy consumption and limit applications in large-scale industries [12]. In our previous research, KAI was able to deliver excellent results compared to conventional techniques. With the existing limitations provide results that are not too far from the UAE method.

In this study, essential extraction factors in KAI consisting of concentration, stir rate, and extraction time were optimized. Several studies related to the optimization of the extraction process of white tea have been done. However, the report is limited to brewing and infusion techniques with variable temperature, extraction time and ethanol concentration $[13,14]$. Optimization of phenolic extraction from green tea using UAE method [12]. Our the best knowledge, there are no research reports on modeling and optimization of richEGCG and polyphenols extraction process using KAI technique with the central composite design approach. The optimum semi-purified extracts were analyzed and characterized using HPLC, FTIR-UATR, P-XRD, and SEM to extraction mechanism analyzed.

\section{MATERIALS AND METHODS}

Plant materials and chemicals

The white tea product of Camellia sinensis L., Theaceae, was obtained from Gamboeng Tea Company member of the Research Institute of Tea and Cinchona Gamboeng, Jawa Barat, Indonesia. The standard EGCG, catechin, gallic acid, caffeine, theobromine, and theophylline were purchased from Sigma Aldrich (St. Louis, MO, USA). The methanol and acetonitrile HPLC-grade were purchased from Fisher Scientific (Loughborough, Leics, UK). The Folin-ciocalteu reagent was purchased from Merck (Darmstadt, Germany).

\section{Kinetic-assisted infundation procedure}

KAI extraction techniques are developed from CIn. In this technique, mechanical stirring is added which differentiates from conventional methods. The solvent used was water by indirect heating at $90{ }^{\circ} \mathrm{C}$ and continued with fractionation using ethyl acetate. The ethyl acetate-soluble target compound was evaporated until the powder was obtained. The semi-purified extracts of white tea obtained were calculated as a percentage of yields.

\section{Optimization design}

The design of experiment (DoE) approach using a central composite design (CCD) was applied to find modeling and to optimize the extraction process of polyphenols (rich-EGCG) in white tea. Quantitative data from experiments are modeled, evaluated, and analyzed using response surface methodology (RSM). This analysis 
with mathematical and statistical techniques is appropriate for problems solving in responses that are influenced by several variables [14]. The main factors as independent variables studied for the development of extraction methods are concentration (water to a material ratio) $(\%, \mathrm{~A})$, stirring rate $(\mathrm{rpm}, \mathrm{B})$, and extraction time (min, C). The responses determined included yields $\left(\%, \mathrm{Y}_{1}\right)$, TPC
( $\% \mathrm{~b} / \mathrm{b}$ GAE, $\left.\mathrm{Y}_{2}\right)$, TFC ( $\% \mathrm{~b} / \mathrm{b}$ CAE, $\left.\mathrm{Y}_{3}\right)$, EGCG ( $\left.\% \mathrm{~b} / \mathrm{b}, \mathrm{Y}_{4}\right)$, caffeine $\left(\% \mathrm{~b} / \mathrm{b}, \mathrm{Y}_{5}\right)$, gallic acid $\left(\% \mathrm{~b} / \mathrm{b}, \mathrm{Y}_{6}\right)$, and theobromine $\left(\% \mathrm{~b} / \mathrm{b}, \mathrm{Y}_{7}\right)$. Based on CCD from the factors entered, 20 runs experiments were obtained. The complete design of all trials is presented in table 1. Each runs with each extraction condition in table 1 was repeated as many as three replications.

Table 1: Design of CCD and experimental results for optimization of KAI uses three dependent variables and seven main responses

\begin{tabular}{|c|c|c|c|c|c|c|c|c|c|c|c|}
\hline \multirow[t]{2}{*}{ Run } & \multirow[t]{2}{*}{ Std } & \multicolumn{3}{|c|}{ Dependent variable } & \multicolumn{7}{|c|}{ Responses (Y)* } \\
\hline & & $\begin{array}{l}\text { A: Conc. } \\
(\%)\end{array}$ & $\begin{array}{l}\text { B:Stirr } \\
\text { rate (\%) }\end{array}$ & $\begin{array}{l}\text { C: Time } \\
\text { (min) }\end{array}$ & $\begin{array}{l}Y_{1}: \\
\text { Yields (\%) }\end{array}$ & $\begin{array}{l}Y_{2}: \\
\text { TPC (\%) }\end{array}$ & $\begin{array}{l}Y_{3}: \\
\text { TFC (\%) }\end{array}$ & $\begin{array}{l}Y_{4}: \\
\text { EGCG (\%) }\end{array}$ & $\begin{array}{l}Y_{5}: \\
\text { Caf (\%) }\end{array}$ & $\begin{array}{l}Y_{6}: \\
\text { GA (\%) }\end{array}$ & $\begin{array}{l}Y_{7}: \\
\text { TB (\%) }\end{array}$ \\
\hline 1 & 3 & 10 & 600 & 10 & 6.41 & 71.56 & 14.93 & 27.46 & 15.98 & 0.110 & 0.418 \\
\hline 2 & 8 & 20 & 600 & 20 & 3.60 & 67.51 & 12.87 & 26.72 & 15.26 & 0.158 & 0.482 \\
\hline 3 & 1 & 10 & 200 & 10 & 6.63 & 70.26 & 14.81 & 25.99 & 15.67 & 0.103 & 0.409 \\
\hline 4 & 20 & 15 & 400 & 15 & 9.20 & 72.06 & 13.82 & 27.54 & 11.61 & 0.162 & 0.327 \\
\hline 5 & 9 & 5 & 400 & 15 & 8.20 & 68.52 & 14.76 & 26.84 & 19.05 & 0.094 & 0.418 \\
\hline 6 & 16 & 15 & 400 & 15 & 9.41 & 70.84 & 13.28 & 28.30 & 12.23 & 0.115 & 0.349 \\
\hline 7 & 12 & 15 & 800 & 15 & 4.10 & 69.88 & 14.35 & 26.25 & 16.41 & 0.161 & 0.488 \\
\hline 8 & 5 & 10 & 200 & 20 & 6.20 & 69.50 & 13.04 & 24.63 & 15.07 & 0.166 & 0.329 \\
\hline 9 & 11 & 15 & 0 & 15 & 4.50 & 70.04 & 13.82 & 28.43 & 13.58 & 0.134 & 0.386 \\
\hline 10 & 7 & 10 & 600 & 20 & 5.10 & 68.25 & 14.25 & 26.65 & 19.34 & 0.137 & 0.417 \\
\hline 11 & 18 & 15 & 400 & 15 & 9.35 & 70.76 & 13.54 & 26.89 & 12.65 & 0.127 & 0.343 \\
\hline 12 & 6 & 20 & 200 & 20 & 3.88 & 66.76 & 12.17 & 26.66 & 13.80 & 0.161 & 0.374 \\
\hline 13 & 17 & 15 & 400 & 15 & 10.50 & 72.87 & 13.87 & 27.52 & 11.62 & 0.144 & 0.336 \\
\hline 14 & 4 & 20 & 600 & 10 & 3.90 & 70.46 & 13.67 & 29.57 & 14.29 & 0.130 & 0.376 \\
\hline 15 & 10 & 25 & 400 & 15 & 2.50 & 67.50 & 12.78 & 28.07 & 14.75 & 0.145 & 0.458 \\
\hline 16 & 14 & 15 & 400 & 25 & 2.89 & 65.15 & 13.16 & 25.23 & 15.79 & 0.164 & 0.430 \\
\hline 17 & 15 & 15 & 400 & 15 & 9.85 & 71.99 & 14.01 & 27.67 & 11.11 & 0.114 & 0.344 \\
\hline 18 & 13 & 15 & 400 & 5 & 5.03 & 68.34 & 14.28 & 31.86 & 14.38 & 0.106 & 0.370 \\
\hline 19 & 2 & 20 & 200 & 10 & 4.06 & 69.35 & 13.28 & 29.72 & 14.51 & 0.111 & 0.377 \\
\hline 20 & 19 & 15 & 400 & 15 & 9.95 & 71.05 & 14.21 & 25.86 & 12.73 & 0.127 & 0.325 \\
\hline
\end{tabular}

*result expressed in mean $(n=3)$

\section{Prediction and verification}

The model of each response $(\mathrm{Y})$ is used to predict the optimal conditions of the extraction process. The optimal condition prediction is obtained by determining the priority value of each response in Design-Expert software. Verification procedures for optimal conditions obtained using six replication data from the experiment. Data were analyzed with one sample t-test sample using SPSS software and analyzed from $95 \%$ confidence interval (CI) and $95 \%$ prediction interval (PI) from Design-Expert software.

\section{Total phenolic content (TPC) assay}

The standard used for the determination of TPC is gallic acid [15-17]. Determination of TPC uses the folin-ciocalteu reagent with the formation of a stable blue color as an important indicator in the reaction. The wavelength used in the absorbance measurement at $740 \mathrm{~nm}$.

\section{Total flavonoid content (TFC) assay}

Determination of TFC using aluminum chloride $(2 \%, \mathrm{~b} / \mathrm{v})$ added to the sample and sodium nitrite $(5 \%, \mathrm{~b} / \mathrm{v})$. Sodium hydroxide solution is used to stop the reaction. The sample absorbance was measured at a wavelength of $510 \mathrm{~nm}$ using the Hitachi U-2900 (Hitachi, Japan) spectrophotometer.

\section{High-performance liquid chromatography}

Quantification of EGCG, catechins, gallic acid, caffeine, theobromine, and theophylline using Hitachi-2000 HPLC instruments (Hitachi, Japan) equipped with UV-Vis L-2420 detector and D-2000 Elite software. The column used for the separation of compounds is LiChrocart reverse phase C18 (Merck, Darmstadt, Germany). Membrane size of $0.45 \mu \mathrm{m}$ is used in filtering the sample, and $20 \mu \mathrm{l}$ was injected into the HPLC system. The quantification of compounds is calculated based on a calibration curve that has been validated previously with a wavelength of $280 \mathrm{~nm}$.

\section{Characterization using FTIR-UATR spectrophotometer}

The FTIR-UATR spectrometer instrument used by Nicolet iS5 (Thermo Scientific, USA) and equipped with Omnic software
(Thermo Scientific, USA) for processing data. The sample powder is loaded in the holder on the instrument. Spectra were recorded in areas of 4000 to $500 \mathrm{~cm}-1$ and a resolution of $4 \mathrm{~cm}-1$.

\section{Characterization using P-XRD}

Characterization of samples from semi-purified extracts of white tea was determined using the MiniFlex600 benchtop X-ray diffractometer (Rigaku, Tokyo, Japan) with the MiniFlex600 PDXL2 software as a data processor. The sample is loaded in a sliding glass and operated at a voltage of $30 \mathrm{kV}$ and $10 \mathrm{~mA}$ with a scan speed of $10 \mathrm{deg} / \mathrm{min}$.

\section{Comparison of extraction methods}

As a comparison, CIn and UAE were used. In the CIn process, the white tea powder is soaked in water at $90^{\circ} \mathrm{C}$ using indirect heating. In the UAE technique, ultrasonic baths (Krisbow, Indonesia) were used with 220$240 \mathrm{AC}$ power, 50 -watt voltage, and $47 \mathrm{kHz}$ frequency. Quantification using HPLC and characterization using FTIR-UATR and P-XRD.

\section{Extraction mechanism analysis using SEM}

Extraction mechanism analysis was carried out by comparing the morphology of tea powder before and after the extraction process using SEM with instrumentation JSM-6510 (Jeol, Tokyo, Japan) based on existing literature $[12,13]$. Briefly, the sample is sprinkled on a carbon plate to form a conductive surface. Operating procedures by setting electron parameters such as high voltage $10 \mathrm{kV}$ and spot size 40 .

\section{Statistical analysis}

Responses and models in optimization were analyzed (including statistical analysis) using Design-Expert software (Stat-Ease Inc., Minneapolis, MN, USA). The quantification data from the HPLC method were statistically analyzed with the help of SPSS software (SPSS Inc, Chicago, IL, USA) with significance at $p<0.05$.

\section{RESULTS AND DISCUSSION}

\section{Optimization studies using CCD}

The effect of concentration (A), stirring rate (B), and extraction time (C) on extraction response is theoretically expected to increase yield 
and polyphenolic compounds (rich-EGCG). The specified extraction factor or variable strongly supports polyphenol compounds to dissolve well [18-20]. In order to obtain high levels of EGCG and polyphenols, a strategy is needed in regulating the material ratio with solvent, temperature, stirring rate, and extraction time. In various literature, EGCG and catechin derivatives will be easily damaged at temperatures above $100{ }^{\circ} \mathrm{C}[10,12,13]$. However, at temperatures lower than $100{ }^{\circ} \mathrm{C}$ for a long time, the EGCG obtained decreases $[11,21]$. Another challenge is the presence of purine alkaloid compounds which are also found in tea leaves, especially caffeine.

Extraction techniques such as conventional maceration and infundation have an equilibrium point [18]. Likewise, with the KAI technique developed. Extraction time is a factor that must be considered in CIn techniques. In the extraction mechanism, there is a minimum time needed for the solvent to penetrate the cell and expand. This condition will make the solvent more effective in dissolving the target compounds contained in cells $[14,19]$. This KAI technique regulates a fixed temperature at $90{ }^{\circ} \mathrm{C}$ referring to the basic technique. Temperature and stirring speed can affect extraction time $[13,18,19,22]$. Temperature dramatically influences solubility of solutes, diffusion coefficients and dielectric water constants $[15,19,23]$. So the KAI technique determines the stirring rate and the extraction time be included in the optimization variable.

The optimization procedure using the DoE approach refers to studies that have been conducted [13, 14, 24, 25]. Optimization of the extraction process with the DoE approach using the DesignExpert software. The design used in DoE is the CCD method part of RSM. The RSM method in many studies is constructive in evaluating and predicting optimal conditions with very complex variables and responses. A CCD is chosen because of its flexibility, easy to understand, and accuracy in predicting optimal conditions [26]. The design in the experimental design uses three independent variables as the main factor and seven main responses. Extraction conditions in each experiment were presented in table 1.

Based on analysis of variance (ANOVA) of the suggested model DesignExpert software, the seven responses showed a significant model $(p<0.05)$ and the lack of fit value was not significant $(p>0.05)$ (table 3$)$. Based on statistical analysis, the equation model of the seven responses $\left(Y_{1}, Y_{2}, Y_{3}, Y_{4}, Y_{5}, Y_{6}\right.$, and $\left.Y_{7}\right)$ evaluated can be used to predict the optimum conditions of the extraction process. Each response to extraction results can be illustrated by the equations model obtained (table 2). Regression equation (table 2) provides an overview of the effect of each factor on the seven responses evaluated. Each component of the factors (A, B, and C) affects the increase or decrease of the response.

Table 2: The regression equation for each response results of the experiment

\begin{tabular}{ll}
\hline Response & Regressed equation \\
\hline Yields $\left(\mathrm{Y}_{1}\right)$ & $\mathrm{Y}_{1}=9.55-1.27 \mathrm{~A}-0.16 \mathrm{~B}-0.41 \mathrm{C}+0.11 \mathrm{AB}+0.16 \mathrm{AC}-0.13 \mathrm{BC}-1.17 \mathrm{~A}^{2}-1.43 \mathrm{~B}^{2}-1.52 \mathrm{C}^{2}$ \\
TPC $\left(\mathrm{Y}_{2}\right)$ & $\mathrm{Y}_{2}=71.62-0.47 \mathrm{~A}+0.10 \mathrm{~B}-1.00 \mathrm{C}+0.23 \mathrm{AB}-0.18 \mathrm{AC}-0.36 \mathrm{BC}-0.88 \mathrm{~A}^{2}-0.40 \mathrm{~B}^{2}-1.20 \mathrm{C}^{2}$ \\
TFC $\left(\mathrm{Y}_{3}\right)$ & $\mathrm{Y}_{3}=13.75-0.56 \mathrm{~A}+0.22 \mathrm{~B}-0.41 \mathrm{C}$ \\
EGCG $\left(\mathrm{Y}_{4}\right)$ & $\mathrm{Y}_{4}=27.39+0.65 \mathrm{~A}-0.06 \mathrm{~B}-1.33 \mathrm{C}$ \\
Caffeine $\left(\mathrm{Y}_{5}\right)$ & $\mathrm{Y}_{5}=12.13-1.05 \mathrm{~A}+0.72 \mathrm{~B}+0.36 \mathrm{C}-0.42 \mathrm{AB}-0.31 \mathrm{AC}+0.70 \mathrm{BC}+1.29 \mathrm{~A}^{2}+0.82 \mathrm{~B}^{2}+0.84 \mathrm{C}^{2}$ \\
Gallic acid $\left(\mathrm{Y}_{6}\right)$ & $\mathrm{Y}_{6}=1.30+0.10 \mathrm{~A}+0.05+0.17 \mathrm{C}$ \\
Theobromine $\left(\mathrm{Y}_{7}\right)$ & $\mathrm{Y}_{7}=0.34+0.01 \mathrm{~A}+0.03 \mathrm{~B}+0.01 \mathrm{C}+0.001 \mathrm{AB}+0.023 \mathrm{AC}+0.024 \mathrm{BC}+0.025 \mathrm{~A}^{2}+0.024 \mathrm{~B}^{2}+0.015 \mathrm{C}^{2}$ \\
\hline
\end{tabular}

An equation model in optimization can provide accurate prediction results by considering the parameters of press value, coefficient of determination $\left(\mathrm{R}^{2}\right)$, adjusted $\mathrm{R}^{2}$, predicted $\mathrm{R}^{2}$, and adequate precision (table 3). The model meets the criteria if the difference between the adjusted $R^{2}$ and predicted $R^{2}$ values are not more than 0.2 , the $R^{2}$ value is more than 0.7 , and the adequate precision value is more than 4 . The press value describes the good fit of a model, and its value is relatively small compared to other models that are being considered.

Table 3: The results of fit statistics of the experimental design

\begin{tabular}{|c|c|c|c|c|c|c|c|c|c|}
\hline Response & Model & Status & SD & $\mathrm{CV}$ & Press & $\mathbf{R}^{2}$ & Adj. $R^{2}$ & $\begin{array}{l}\text { Pred. } \mathbf{R}^{2} \\
\end{array}$ & Adeq. preci. \\
\hline Yields $\left(\mathrm{Y}_{1}\right)$ & Quadratic & $\begin{array}{l}\text { Model significant, Lack of fit not } \\
\text { significant }\end{array}$ & 0.72 & 11.50 & 33.48 & 0.9618 & 0.9274 & 0.7534 & 14.1554 \\
\hline $\mathrm{TPC}\left(\mathrm{Y}_{2}\right)$ & Quadratic & $\begin{array}{l}\text { Model significant, Lack of fit not } \\
\text { significant }\end{array}$ & 0.77 & 1.11 & 24.12 & 0.9198 & 0.8475 & 0.6739 & 12.4831 \\
\hline $\operatorname{TFC}\left(\mathrm{Y}_{3}\right)$ & Linear & $\begin{array}{l}\text { Model significant, Lack of fit not } \\
\text { significant }\end{array}$ & 0.33 & 2.40 & 2.80 & 0.8304 & 0.7986 & 0.7274 & 16.1523 \\
\hline EGCG $\left(\mathrm{Y}_{4}\right)$ & Linear & $\begin{array}{l}\text { Model significant; Lack of fit not } \\
\text { significant }\end{array}$ & 1.04 & 3.80 & 29.67 & 0.6707 & 0.6089 & 0.4360 & 11.4668 \\
\hline Caffeine $\left(\mathrm{Y}_{5}\right)$ & Quadratic & $\begin{array}{l}\text { Model significant, Lack of fit not } \\
\text { significant }\end{array}$ & 0.72 & 4.97 & 26.66 & 0.9455 & 0.8964 & 0.7197 & 14.2884 \\
\hline Gallic acid $\left(\mathrm{Y}_{6}\right)$ & Linear & $\begin{array}{l}\text { Model significant, Lack of fit not } \\
\text { significant }\end{array}$ & 0.13 & 9.93 & 0.41 & 0.7142 & 0.6606 & 0.5555 & 11.9532 \\
\hline $\begin{array}{l}\text { Theobromine } \\
\left(\mathrm{Y}_{7}\right)\end{array}$ & Quadratic & $\begin{array}{l}\text { Model significant, Lack of fit not } \\
\text { significant }\end{array}$ & 0.01 & 3.08 & 0.008 & 0.9707 & 0.9444 & 0.8268 & 18.7813 \\
\hline
\end{tabular}

The response of yields $\left(\mathrm{Y}_{1}\right)$ from a measurement of 20 experiments scattered around the diagonal line on the normal plot of residuals curve (fig. 1-A). This result indicates that the data is usually distributed and meets the requirements for the ANOVA test. Functional modeling is indicated by the absence of suggestions for transforming the Design-Expert software. Predicted vs. actual curves are used to detect values, or groups of values, that are not easily predicted by the model. The predicted and actual values of yields are not much different (fig. 1-B) with the adjusted $\mathrm{R}^{2}$ and predicted $\mathrm{R}^{2}$ difference indicators of 0.17 (less than 0.2 ). This result indicates that there is no significant difference between the observation data and the predicted data from the suggested model.

Low or too high concentrations and stirring rates tend to reduce yields. The optimal yields are marked in the reddish-orange area (fig. 1-C and 1-D). The $p$-value in the $\mathrm{Y}_{1}$ model is less than 0.05 indicating a significant model requirement. In this case factors $\mathrm{A}$, $C, A^{2}, B^{2}, C^{2}$ are significant models with the selected type of model is quadratic. The yields $\left(Y_{1}\right)$ will be optimal in a specific concentration range $(\mathrm{A})$ and decrease the yields by increasing 
the concentration $\left(\mathrm{A}^{2}\right)$. The addition of extraction time $\left(\mathrm{C}^{2}\right)$ will reduce the yields; the more extraction time is indeed not
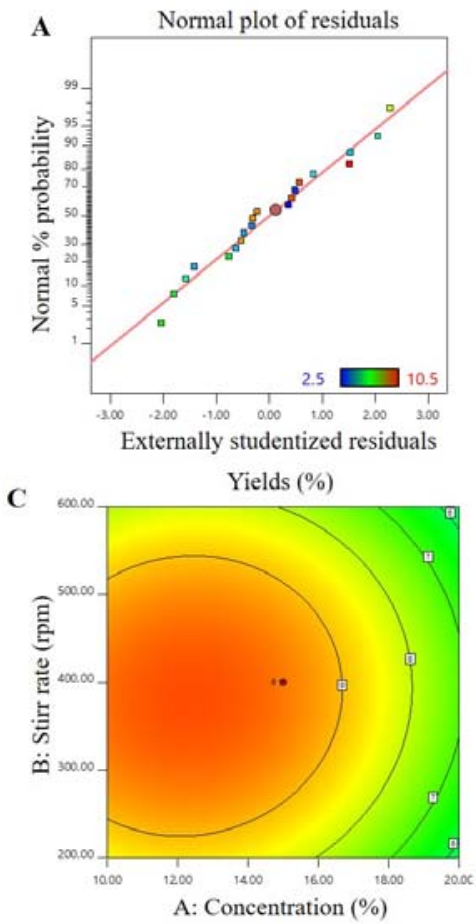

desirable in production. The stirring rate (B) affects the yields, especially the increase in stirring will reduce the extracts.

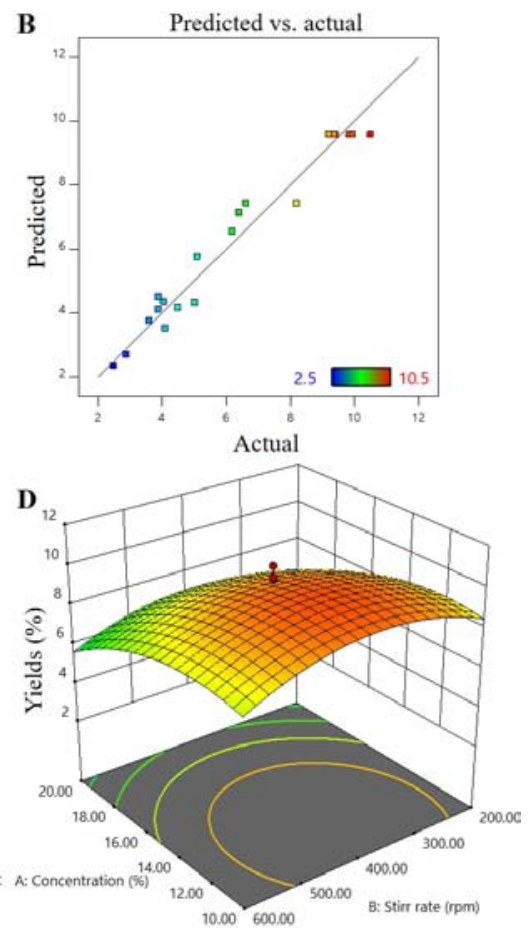

Fig. 1: Model analysis results for response yields $\left(\mathrm{Y}_{1}\right)$, normal plot of residuals curves (A), prediction vs. actual curves (B), contour plots (C), and 3D surface plots (D)

The yield ranges from 2.5 to $10.5 \%$ and is significantly influenced by concentration, stirring rate and extraction time at a 0.05 significance level. The yields value of $2.5 \%$ is obtained with the following extraction conditions, $25 \%$ for concentration, $400 \mathrm{rpm}$ for stirring rate, and $15 \mathrm{~min}$ for extraction time. The yield value of $10.5 \%$ is obtained by extraction conditions similar to the difference in concentration of $15 \%$. Extraction results (especially yields) obtained are better than existing studies $[10,13,14]$.
Systematically and scientifically, the DoE approach will provide a better interpretation. The relationship between the response $(\mathrm{Y})$ and factors $(\mathrm{A}$, $\mathrm{B}$, and $\mathrm{C}$ ) is presented in contour plots (fig. 2) and 3D surface plots (fig. 3). Contour plots on fig. 2, describes the relationship between the factors determined by the response of TPC, TFC, EGCG, caffeine, gallic acid, and theobromine. All responses have data spread in a diagonal line on the normal plot of residuals curve. Therefore, the seven equation models in the response meet the requirements in the ANOVA test. 
A
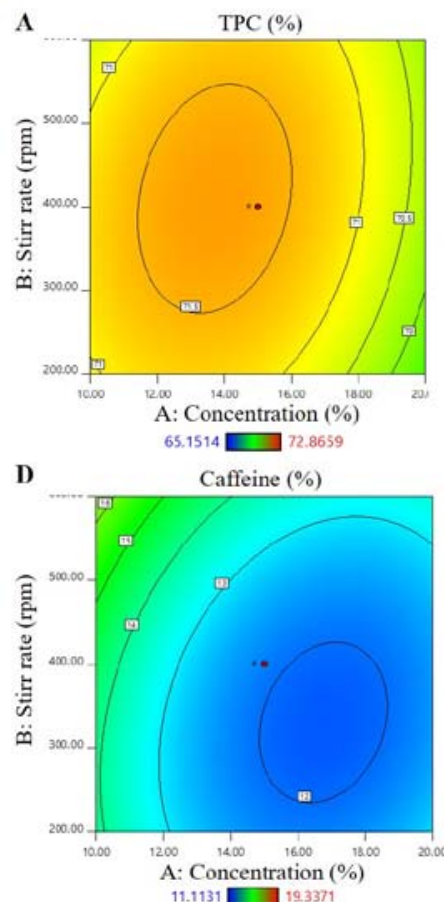

B

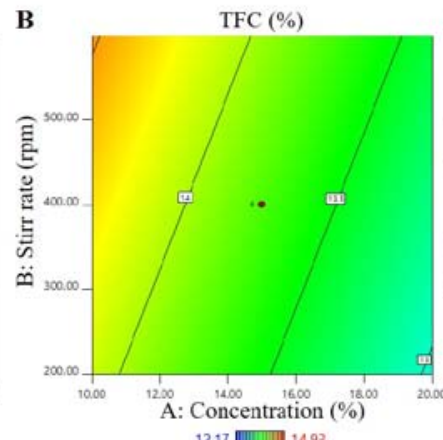

E

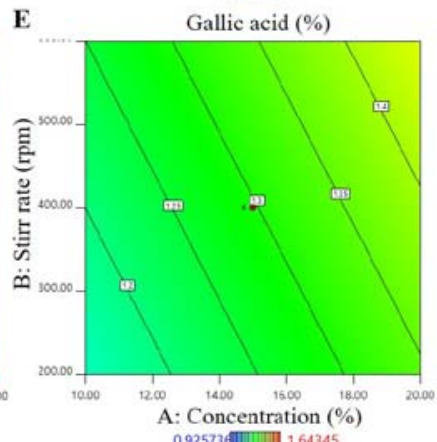

C

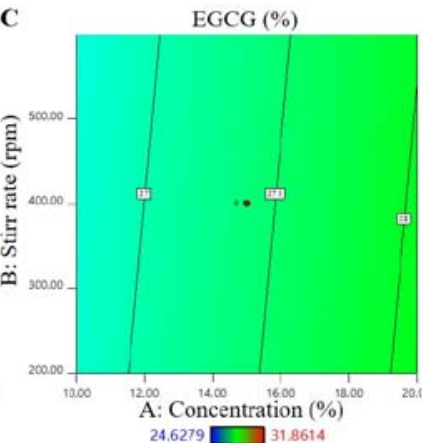

F

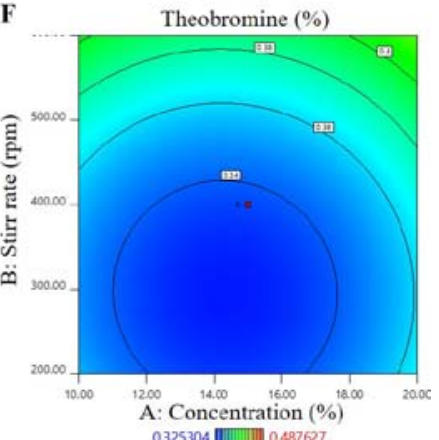

Fig. 2: Contour plots from TPC (A), TFC (B), EGCG (C), caffeine (D), gallic acid (E), and theobromine (F) responses

Contour plots on linear and quadratic models have different characteristics, as well as 3D surface plots. In models with linear types, contour plots (fig. 2-B, 2-C, and 2-E) areas are marked with diagonal lines. Model with quadratic type, area marked with circular lines (fig. 2-A, 2-D, and 2-F). The quadratic model has the optimal value of the response in the range constraints so that the area is marked with a circular line. For the 3D surface plot, the model with linear type surface looks flat (fig. 3-B, 3-C, and 3-E), while for quadratic the surface will look concave or convex (fig. 3-A, 3-D, and 3-F).
As with the $\mathrm{Y}_{1}$ response, the response for TPC $\left(\mathrm{Y}_{2}\right)$ has significant $\mathrm{A}$, $C, A^{2}, B^{2}, C^{2}$ factors on the quadratic model. Increasing concentration $\left(\mathrm{A}^{2}\right)$, stirring rate $\left(\mathrm{B}^{2}\right)$, and extraction time $\left(\mathrm{C}^{2}\right)$ will reduce TPC. Based on 20 experimental runs, obtained TPC values of 65.15 to $72.87 \%$ (GAE \% b/b). Extraction conditions at run 1 (table 1) produce the highest TFC, which is $14.93 \%$ (CAE \% b/b). The highest EGCG was $31.86 \% \mathrm{~b} / \mathrm{b}$ which was found at run 18, while the lowest value was $24.63 \% \mathrm{~b} / \mathrm{b}$ at run 8 . The EGCG levels in some tea leaf extraction techniques ranged from 1.5 to $30 \% \mathrm{~b} / \mathrm{b}[13,14]$.
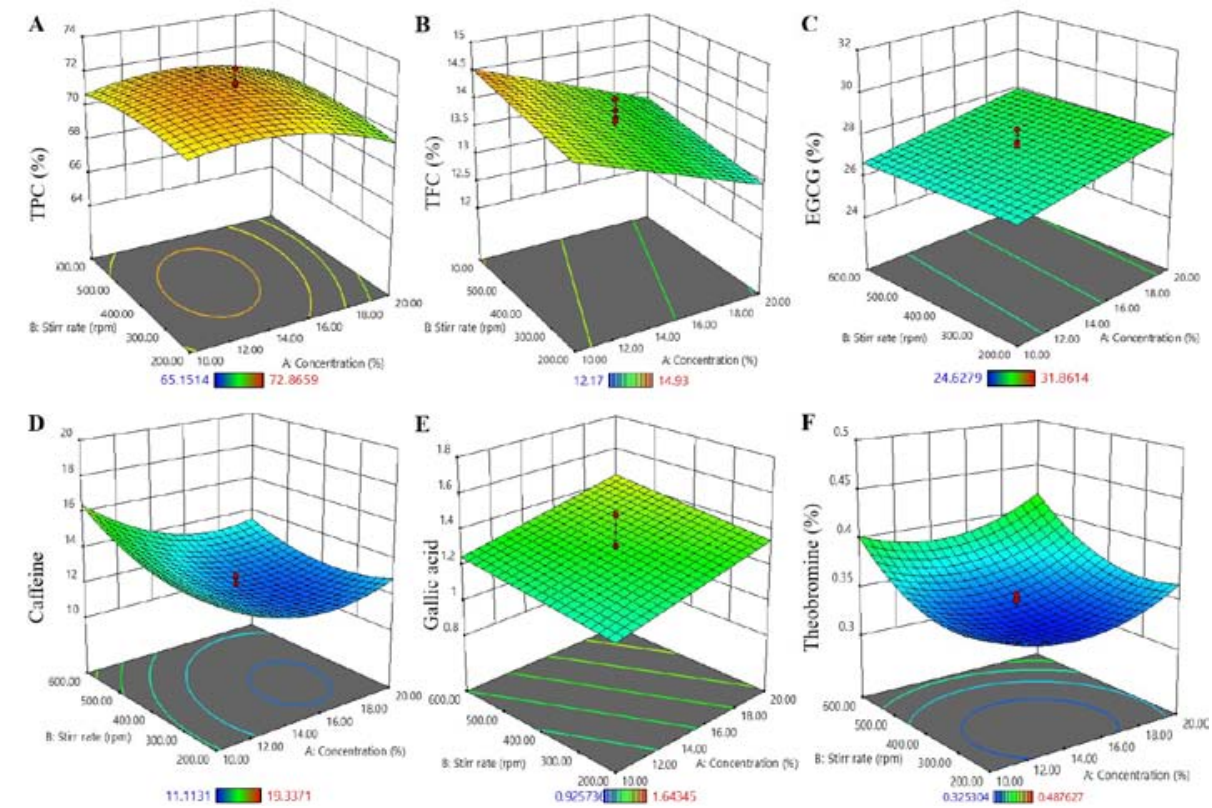

Fig. 3: 3D surface plots from TPC (A), TFC (B), EGCG (C), caffeine (D), gallic acid (E), and theobromine (F) responses

For optimization purposes, especially the selection of responses, catechin and theophylline data were excluded because the extract samples were too low (results of measurement orientation with HPLC/UV-detection). Also, the primary target is EGCG while still considering caffeine as a representative of purine alkaloids (both compounds have high levels). Therefore, catechins and theophylline can be ignored because they do not affect the results of extraction.

The optimum conditions for extraction and verification 
Desirability value is used as an important indicator in determining optimum conditions. Desirability values close to 1 indicate proximity to predicted values. The extraction condition with desirability value 0.678 will give $9.32 \%$ for yields, $71.86 \% \mathrm{~b} / \mathrm{b}$ GAE for TPC, $14.04 \%$ $\mathrm{b} / \mathrm{b}$ CAE for TFC, $28.06 \% \mathrm{~b} / \mathrm{b}$ for EGCG, $12.33 \% \mathrm{~b} / \mathrm{b}$ for caffeine, $1.21 \% \mathrm{~b} / \mathrm{b}$ for gallic acid, and $0.34 \% \mathrm{~b} / \mathrm{b}$ for theobromine. The point of intersection of optimal conditions can be seen in the contour plot with a desirability value of 0.678 (fig. 4).

Predictive values are obtained through prediction of points which consist of $95 \% \mathrm{CI}$ and $95 \% \mathrm{PI}$. The confidence interval is the average range of observations at a $95 \%$ confidence level. Prediction interval is the range of individual predictive values observed at $95 \%$ level of confidence [26].

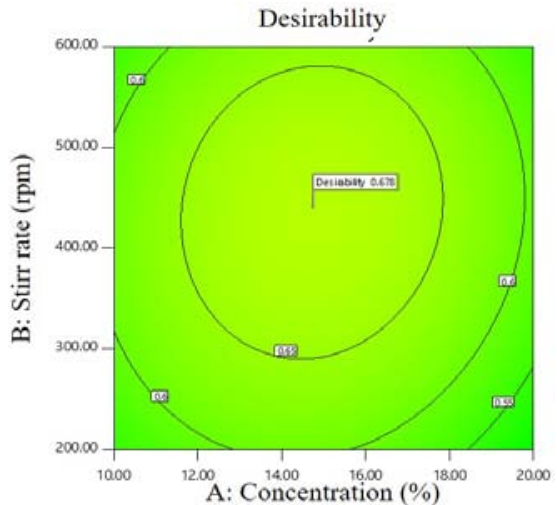

Fig. 4: Desirability value at optimal conditions of extraction process using KAI

Table 4: The predictive value of optimum conditions and verification range

\begin{tabular}{|c|c|c|c|c|c|c|c|c|}
\hline \multirow[t]{2}{*}{ Response } & \multirow{2}{*}{$\begin{array}{l}\text { Prediction } \\
(\%)\end{array}$} & \multirow{2}{*}{$\begin{array}{l}\text { Observation* } \\
(\%)\end{array}$} & \multirow{2}{*}{$\begin{array}{l}\text { Shapiro- } \\
\text { Wilk test }^{* *}\end{array}$} & \multirow{2}{*}{$\begin{array}{l}\text { One } \\
\text { t-test }\end{array}$} & \multicolumn{2}{|c|}{$95 \%$ CI } & \multicolumn{2}{|c|}{$95 \%$ PI } \\
\hline & & & & & Low & High & Low & High \\
\hline Yields $\left(\mathrm{Y}_{1}\right)$ & 9.32 & $9.34 \pm 0.05$ & 0.495 & 0.314 & 8.69 & 9.95 & 7.60 & 11.05 \\
\hline $\mathrm{TPC}\left(\mathrm{Y}_{2}\right)$ & 71.86 & $70.97 \pm 1.29$ & 0.668 & 0.154 & 71.19 & 72.54 & 70.02 & 73.71 \\
\hline $\mathrm{TFC}\left(\mathrm{Y}_{3}\right)$ & 14.04 & $13.98 \pm 0.46$ & 0.968 & 0.631 & 13.85 & 14.22 & 13.31 & 14.76 \\
\hline EGCG $\left(\mathrm{Y}_{4}\right)$ & 28.06 & $29.02 \pm 0.95$ & 0.522 & 0.057 & 27.48 & 28.65 & 25.78 & 30.35 \\
\hline Caffeine $\left(\mathrm{Y}_{5}\right)$ & 12.33 & $11.95 \pm 0.99$ & 0.341 & 0.396 & 11.70 & 12.96 & 10.60 & 14.05 \\
\hline Gallic acid ( $\left.\mathrm{Y}_{6}\right)$ & 1.21 & $1.33 \pm 0.12$ & 0.374 & 0.075 & 1.14 & 1.28 & 0.93 & 1.49 \\
\hline Theobromine $\left(\mathrm{Y}_{7}\right)$ & 0.34 & $0.33 \pm 0.01$ & 0.071 & 0.134 & 0.33 & 0.35 & 0.31 & 0.37 \\
\hline
\end{tabular}

*result expressed in mean $n=6 \pm$ standard deviation (SD), ${ }^{* *} p>0.05$ )

The yields at optimum conditions were $9.34 \pm 0.05 \%$, theoretically included in the $95 \%$ CI verification range ( 8.69 to $9.95 \%$ ) and from the $95 \%$ PI range (7.60 to $11.05 \%$ ) well verified. Verification can be determined from one sample t-test with a $p$-value of more than 0.05 (table 4). This one sample t-test test shows that the yields are not significantly different from the predicted value. TPC, TFC, EGCG, caffeine, gallic acid, and theobromine levels were also well verified (based on $95 \% \mathrm{CI}$ range, $95 \% \mathrm{PI}$ range, and one sample t-test).

Observation results for each response enter the range of predictive values. Accuracy in predicting response is related to modeling obtained from CCD results and excellent statistical analysis. Polyphenolic compounds with parameters of TPC, TFC, EGCG, and gallic acid at optimal extraction conditions obtained high results, were $70.97 \pm 1.29 \%, 13.98 \pm 0.46 \%, 29.02 \pm 0.95 \%$, and $1.33 \pm 0.12 \%$,
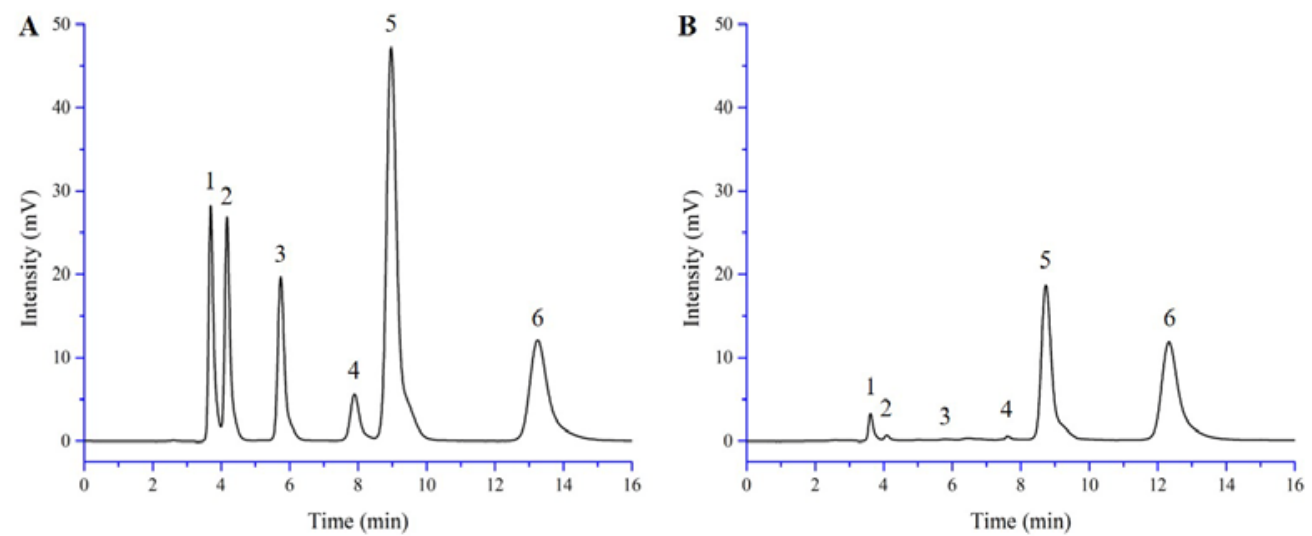

Fig. 5: The HPLC chromatogram of standards (A) and profile of white tea extracts from kinetic-assisted infundation (B), Peaks: gallic acid (1), theobromine (2), theophylline (3), catechin (4), caffeine (5), and epigallocatechin gallate (6)

Fig. 6 presents the levels of several active compounds resulting from extraction techniques using KAI, CIn, and UAE. EGCG compounds are the main target in the development of extraction techniques in this respectively. In this study, caffeine and theobromine compounds were set minimum in the prediction priority assessment. The results of extraction using KAI obtained $11.95 \pm 0.99 \%$ for caffeine and $0.33 \pm 0.01 \%$ for theobromine.

\section{Characterization of semi-purified extract using HPLC}

The optimal condition of the extraction process from the KAI technique is then characterized using the HPLC, FTIR-UATR and PXRD methods. The HPLC chromatogram profile shows the presence of EGCG, caffeine, gallic acid, and theobromine compounds with a stronger intensity (fig. 5). In fig. 5-A, the six standards can be appropriately separated. EGCG in white tea extract (fig. 5-B) has a peak with a tendency to be the same as the standard. The HPLC results in the extract showed low intensity for catechin and theobromine compounds. remain measured (fig. 6). EGCG levels in semi-purified extract of white tea obtained from KAI, CIn, and UAE were $29.02 \pm 0.95 \%$, 
$24.26 \pm 0.63 \%, 30.44 \pm 0.74 \%$, respectively. Caffeine is a class of purine alkaloids; this compound is also found in black tea, green tea, and white tea $[27,28]$. The caffeine content in the semi-purified extract sample was $11.95 \pm 0.99$ for KAI, $15.51 \pm 0.60 \%$ for CIn, and $18.06 \pm 0.57 \%$ for UAE. Caffeine and theobromine in KAI are lower than those of CIn and UAE, and these results are as expected. Ultrasonic wave penetration in the UAE causes cells or tissues to be damaged so that all compounds can quickly dissolve in the solvent. In KAI optimization results, the model and priority determination are set so that alkaloids such as caffeine can be minimized.
A
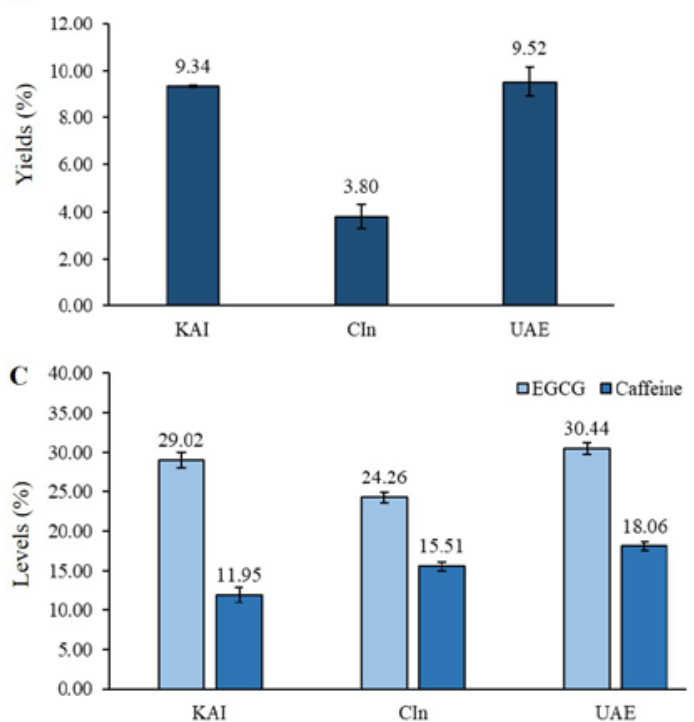

B

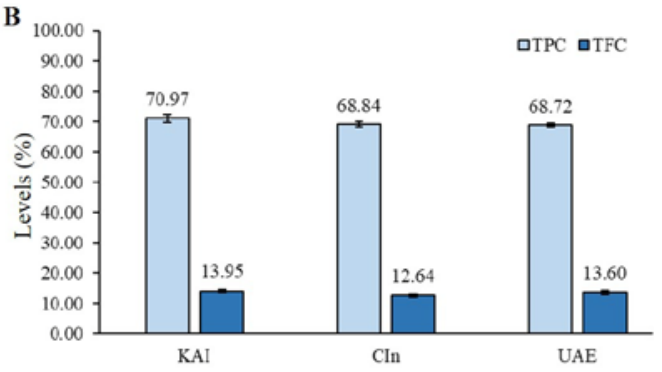

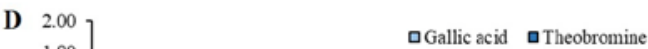

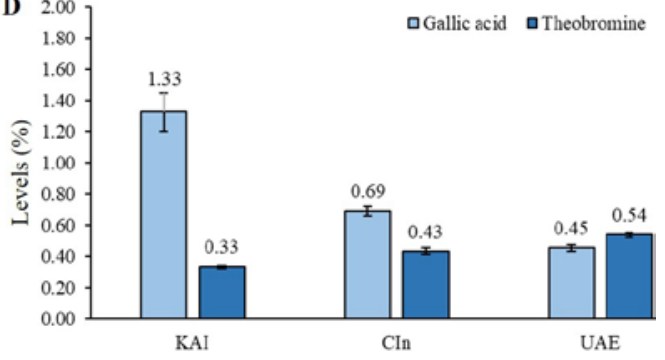

Fig. 6: Comparison of white tea extract using KAI, CIn, and UAE, yield of extracts (A), TPC and TFC (B), EGCG and Caffeine (C), and gallic acid, and theobromine (D), $(n=6)$

For the purpose of comparing the extraction results from KAI, CIn, and UAE, the levels of catechins and theophylline were measured, although in the optimization analysis these two parameters were not determined. Catechins and theophylline in white tea extracts produced by KAI and CIn were relatively lower than other compounds. Catechins in CIn were not detected, but in UAE techniques were relatively higher than KAI and CI. The catechin and theophylline levels in UAE techniques are caused by ultrasonic waves which can assist in attracting compounds.

\section{Profiling using FTIR-UATR spectrophotometer}

High polyphenols content (especially EGCG) in white tea extract powder will be easily analyzed using FTIR instruments [29]. In general, hydroxyl and carbonyl groups provide vibration bands that are easily detected [30-32]. Analysis using FTIR has been done to characterize extracts and medicinal raw materials. Fig. 7, shows the FTIR-UATR spectrum of white tea extract powder produced by KAI, CIn, UAE, EGCG standard, and caffeine.

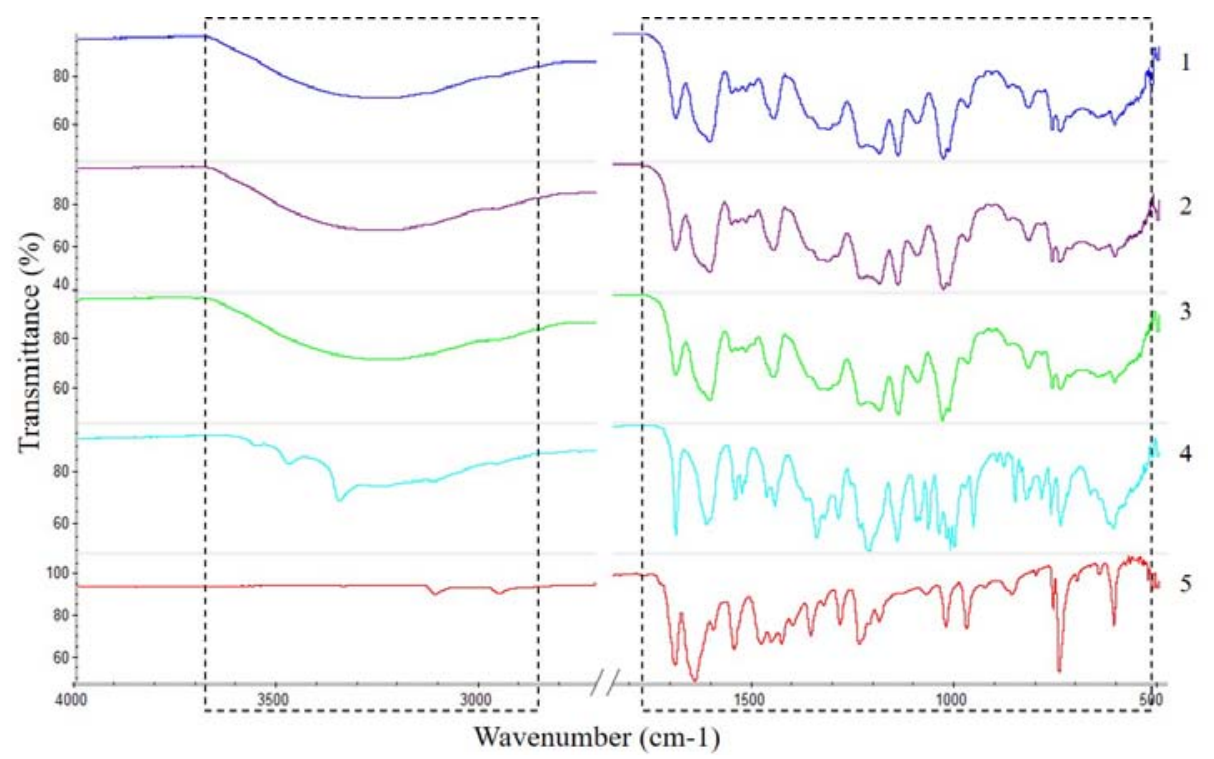

Fig. 7: FTIR-UATR spectra of white tea extracts using KAI (1), CIn (2), UAE (3), standard EGCG (4), and caffeine (5)

Extract results from the UAE and CIn provide a spectral pattern that is similar qualitatively to the KAI method. Based on the spectra, there are strong and broad $\mathrm{O}-\mathrm{H}$ stretch bands in the area of 3600 to
$2800 \mathrm{~cm}-1$ for extract powder produced by KAI, CIn, UAE, and EGCG. Spectra at a wavelength of 1800 to $800 \mathrm{~cm}-1$ prove the presence of carbonyl polyphenols. The spectrum with an area of 3600 to 2800 
$\mathrm{cm}-1$ is the first unique feature, and the area of 1800 to $800 \mathrm{~cm}-1$ is a sign of the second unique feature. Characteristics of polyphenols are seen in the number of $\mathrm{OH}$ in the area of 3500 to $3100 \mathrm{~cm}-1$ [31]. Bands in the $1689.84 \mathrm{~cm}-1$ for KAI, $1690.11 \mathrm{~cm}-1$ for CIn, and $1689.60 \mathrm{~cm}-1$ are related to the vibration of the carboxyl group stretching, stretching $\mathrm{C}=0$ flavonoids. A band $1552.16 \mathrm{~cm}-1$ for the KAI sample related to aromatic stretching $\mathrm{C}=\mathrm{C}$. Stretching of aromatic carbon at $741.18 \mathrm{~cm}-1$ for the KAI spectra is similar to the EGCG spectrum pattern at $740.20 \mathrm{~cm}-1$.

Referring to caffeine spectra, extract powder from KAI, CIn, and UAE results have a weak peak in the area of 3100 to $2900 \mathrm{~cm}-1$. Caffeine has a unique spectral pattern on the $3111.93 \mathrm{~cm}-1$ bands and $2953.90 \mathrm{~cm}-1$ bands. As with EGCG, caffeine has a typical spectrum at $1800-800 \mathrm{~cm}-1$ with different patterns. Therefore, semi-purified extract powder from white tea has a spectral pattern combined between catechin derivatives (mainly EGCG) and purine alkaloids (which are dominated by caffeine).

\section{Profiling using powder X-ray diffraction}

Characterization of material from the existing literature can be done using the XRD diffractogram pattern [33-36]. The diffractogram sample of powdered white tea extract is shown in fig. 8. The characteristic peaks of white tea extract centered at 10 and 20 degrees (2-theta) according to the crystallographic field, which indicates a highly crystalline material in samples. The diffractogram pattern of extracts of KAI and CIn has similarities with higher intensity in KAI. The sample extract from UAE has a much lower intensity than KAI and conventional techniques with almost the same pattern. In this study, the diffractogram pattern was used as a unique fingerprint marker that distinguished between KAI, UAE, and CIn extraction techniques.

The crystalline form of the chemical in the powder X-ray diffraction pattern can form unique fingerprints. In one chemical compound, there can be more than one crystal form; this phenomenon is known as polymorphism. Different polymorphs of the same compound can show very different solubility and bioavailability properties.

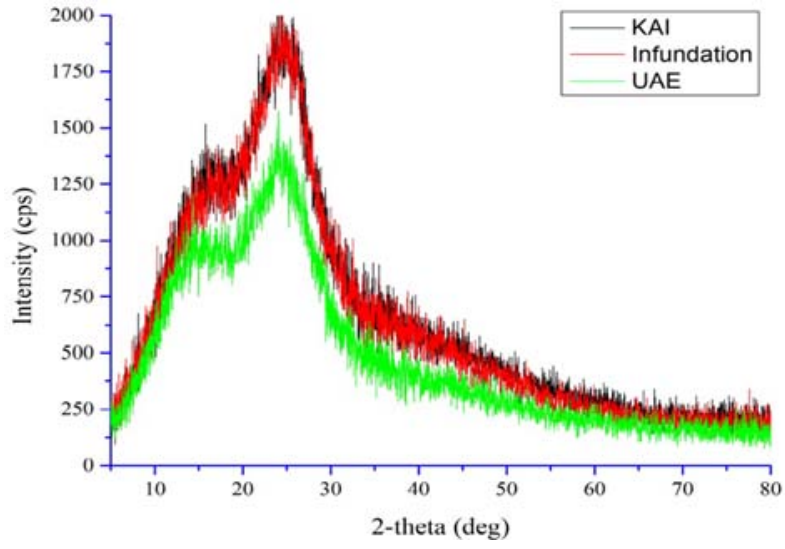

Fig. 8: The XRD pattern semi-purified extracts of white tea using KAI (black), CIn (red), and UAE (green)

\section{Extraction mechanism}

Several studies have reported changes in cell wall surface morphology due to the extraction process [37-39]. Analysis using SEM instrumentation aims to evaluate changes in cell wall surface with more specific morphological observations [37]. Based on the results of SEM, there were significant physical changes to the surface of the cell walls of white tea powder matrix before and after KAI treatment (fig. 9). White tea powder before extraction (fig. 9-A) has good morphology with intact cell walls. The remaining white tea powder from KAI and CIn shows the cell wall that has been damaged. In the KAI technique, the cell wall suffered more severe damage.

From the matrix morphology, there was an evident microstructure change from white tea powder after extraction using KAI compared to conventional techniques. Extraction efficiency using KAI can be attributed to optimum stirring rate conditions and extraction time to cause damage to the cell wall surface. The effect of the damaged cell wall facilitates the release of solutes in the sample matrix into the solution $[37,39]$. This theory correlates with the results of the content of TPC, TFC, and EGCG resulting from the extraction process. The efficiency of the KAI method is higher than the CIn method which causes damage to the cell wall surface of white tea powder.
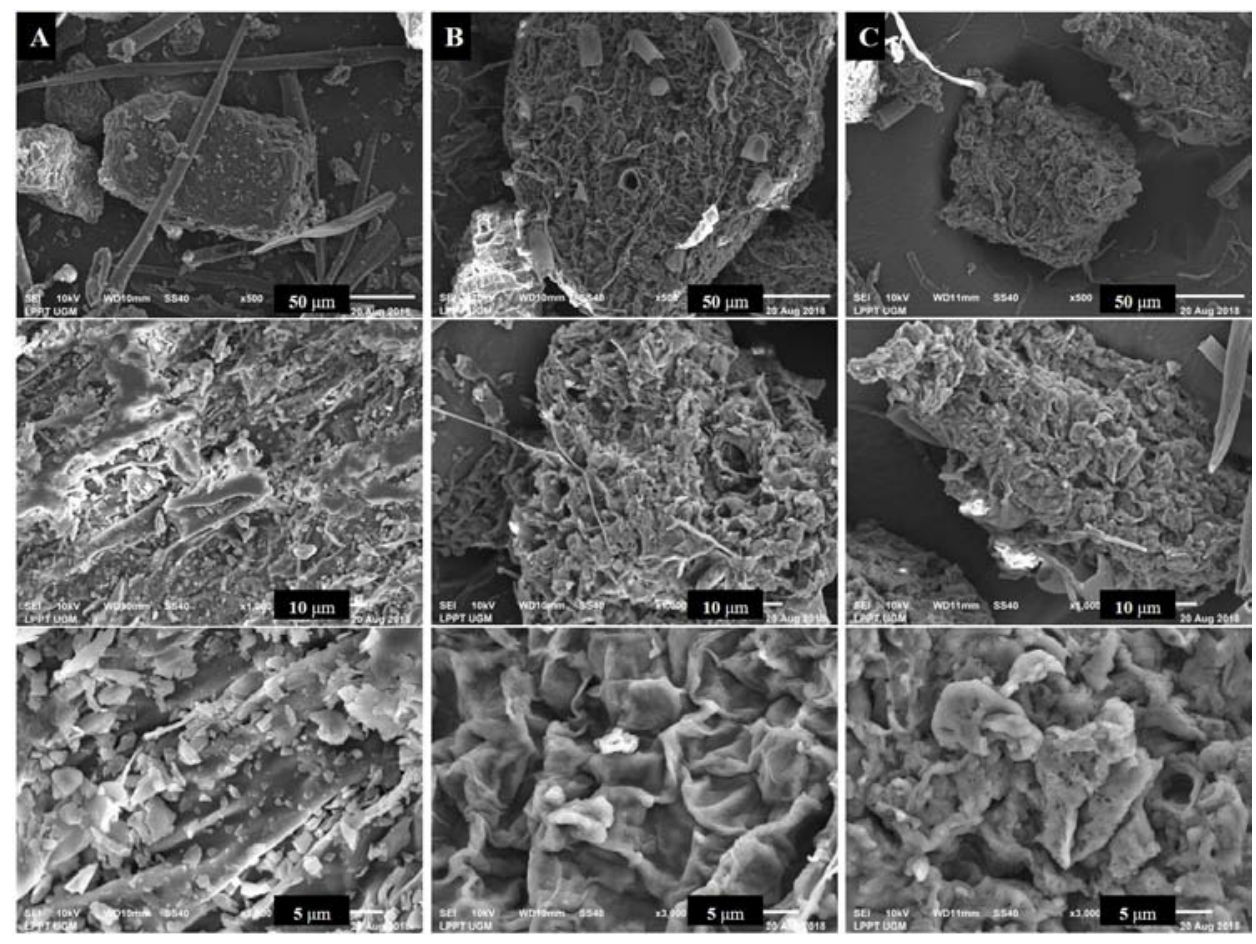
Fig. 9: SEM micrograhp of powder white tea before extraction (A), after extraction using KAI (B), and CIn (C)

\section{CONCLUSIONN}

Optimization of the extraction process using the DoE with CCD approach was successfully applied to evaluate and obtain optimal conditions from the KAI technique. A novel technique for extracting white tea using KAI was successfully developed and proved to provide better results than conventional techniques. The optimum conditions in the KAI technique include $14.75 \%$ concentration (water to the material ratio), $440 \mathrm{rpm}$ for the stirring rate, and 12.31 min for the extraction time.

\section{ACKNOWLEDGMENT}

The authors thank the Beasiswa Unggulan Dosen Indonesia Dalam Negeri (BUDI DN; contract number 20161141040054) and Lembaga Dana Dana Pendidikan (LPDP) Indonesia for providing financial support to conduct these research and sponsorship.

\section{AUTHORS CONTRIBUTIONS}

All authors listed in the manuscript contribute equally

\section{CONFLICT OF INTERESTS}

The author declares there is no conflict of interest

\section{REFERENCES}

1. Tan J, Engelhardt UH, Lin Z, Kaiser N, Maiwald B. Flavonoids, phenolic acids, alkaloids and theanine in different types of authentic Chinese white tea samples. J Food Compos Anal 2017; 57:8-15.

2. Dai W, Xie D, Lu M, Li P, Lv H, Yang C, et al. Characterization of white tea metabolome: Comparison against green and black tea by a nontargeted metabolomics approach. Food Res Int 2017;96:40-5.

3. Alves MG, Martins AD, Teixeira NF, Rato L, Oliveira PF, Silva BM. White tea consumption improves cardiac glycolytic and oxidative profile of prediabetic rats. J Funct Foods 2015;14:102-10.

4. Shiyan S, Herlina H, Bella M, Amriani A. Antiobesity and antihypercholesterolemic effects of white tea (Camellia sinensis) infusion on high-fat diet induced obese rats. Pharmaciana 2017;7:278-88.

5. Almajano MP, Vila I, Gines S. Neuroprotective effects of white tea against oxidative stress-induced toxicity in striatal cells. Neurotox Res 2011;20:372-8.

6. Hajiaghaalipour F, Kanthimathi MS, Sanusi J, Rajarajeswaran J. White tea (Camellia sinensis) inhibits proliferation of the colon cancer cell line, HT-29, activates caspases and protects DNA of normal cells against oxidative damage. Food Chem 2015;169:401-10.

7. Shiyan S, Herlina H, Rizkika Sari L. Nephroprotective of anthocyanin pigments extract from red cabbage (Brassica oleracea L. Var. Capitata f. Rubra) against gentamicin-captoprilinduced nephrotoxicity in rats. Asian J Pharm Clin Res 2018;11:432.

8. Zhong J, Xu C, Reece EA, Yang P. The green tea polyphenol EGCG alleviates maternal diabetes-induced neural tube defects by inhibiting DNA hypermethylation. Am J Obstet Gynecol 2016;215:368. e1-368. e10.

9. Dias TR, Tomas G, Teixeira N, Alves M, Oliveira P, Silva BM. White tea (Camellia sinensis (L.)): antioxidant properties and beneficial health effects. Int J Food Sci Nutr Diet 2013;2:19-26.

10. Widyaningrum N, Fudholi A, Sudarsono, Setyowati EP. Stability of epigallocatechin gallate (EGCG) from green tea (Camellia sinensis) and its antibacterial activity against staphylococcus epidermidis ATCC 35984 and propionibacterium acnes ATCC 6919. Asian J Biol Sci 2015;8:93-101.

11. da Silveira TFF, Meinhart AD, Ballus CA, Godoy HT. The effect of the duration of infusion, temperature, and water volume on the rutin content in the preparation of mate tea beverages: an optimization study. Food Res Int 2014;60:241-5.

12. Lee LS, Lee N, Kim YH, Lee CH, Hong SP, Jeon YW, et al. Optimization of ultrasonic extraction of phenolic antioxidants from green tea using response surface methodology. Molecules 2013;18:13530-45.

13. Zielinski AAF, Haminiuk CWI, Beta T. Multi-response optimization of phenolic antioxidants from white tea (Camellia sinensis L. Kuntze) and their identification by LC-DAD-Q-TOFMS/MS. LWT-Food Sci Technol 2016;65:897-907.

14. Peiro S, Gordon MH, Blanco M, Perez-Llamas F, Segovia F, Almajano MP. Modelling extraction of white tea polyphenols: the influence of temperature and ethanol concentration. Antioxidants 2014;3:684-99.

15. Li F, Mao YD, Wang YF, Raza A, Qiu LP, Xu XQ. Optimization of ultrasonic-assisted enzymatic extraction conditions for improving total phenolic content, antioxidant and antitumor activities in vitro from Trapa quadrispinosa Roxb. residues. Molecules 2017;22:396-413.

16. Damiani E, Bacchetti T, Padella L, Tiano L, Carloni P. Antioxidant activity of different white teas: comparison of hot and cold tea infusions. J Food Compos Anal 2014;33:59-66.

17. Pradeepa M, Kalidas V, Geetha N. Qualitative and quantitative phytochemical analysis and bactericidal activity of Pelargonium graveolens L'her. Int J Appl Pharm 2016;8:7-11.

18. Pereira SV, Reis RASP, Garbuio DC, Freitas LAP de. Dynamic maceration of Matricaria chamomilla inflorescences: optimal conditions for flavonoids and antioxidant activity. Rev Bras Farmacogn 2018;28:111-7.

19. Costa Machado ARM, Bastos JK, de Freitas LAP. Dynamic maceration of Copaifera langsdorffi leaves: a technological study using fractional factorial design. Rev Bras Farmacogn 2013;23:79-85.

20. Zhou J, Zheng X, Yang Q, Liang Z, Li D, Yang X, et al. Optimization of ultrasonic-assisted extraction and radicalscavenging capacity of phenols and flavonoids from Clerodendrum cyrtophyllum Turcz leaves. PLoS One 2013;8:1-8.

21. Yan L, Xi J. Micro-mechanism analysis of ultrahigh pressure extraction from green tea leaves by numerical simulation. Sep Purif Technol 2017;180:51-7.

22. Hou W, Zhang W, Chen G, Luo Y. Optimization of extraction conditions for maximal phenolic, flavonoid and antioxidant activity from Melaleuca bracteata leaves using the response surface methodology. PLoS One 2016;11:e0162139.

23. Cui HY, Murthy HN, Moh SH, Cui YY, Lee EJ, Paek KY. Comparison of conventional and ultrasound-assisted methods for extraction of nutraceutical compounds from Dendrobium candidum. CyTA J Food 2014;12:355-9.

24. Guo L, Zhu W, Xu F, Liu M, Xie Y, Zhang J. Optimized ultrasonicassisted extraction of polysaccharides from Cyclina sinensis and evaluation of antioxidant activities in vitro. CyTA J Food 2014;12:32-9.

25. Alara OR, Abdurahman NH, Olalere OA. Optimization of microwave-assisted extraction of flavonoids and antioxidants from Vernonia amygdalina leaf using response surface methodology. Food Bioprod Proc 2018;107:36-48.

26. Weissman SA, Anderson NG. Design of experiments (DoE) and process optimization. A review of recent publications. Org Proc Res Dev 2015;19:1605-33.

27. Bae IK, Ham HM, Jeong MH, Kim DH, Kim HJ. Simultaneous determination of 15 phenolic compounds and caffeine in teas and mate using RP-HPLC/UV detection: method development and optimization of extraction process. Food Chem 2015;172:469-75.

28. Fernando CD, Soysa P. Simple isocratic method for simultaneous determination of caffeine and catechins in tea products by HPLC. Springerplus 2016;5:970.

29. Grasel F, dos S, Ferrao MF, Wolf CR. Development of methodology for identification the nature of the polyphenolic extracts by FTIR associated with multivariate analysis. Spectrochim Acta Part A 2016;153:94-101.

30. Cai J, Wang Y, Xi X, Li H, Wei X. Using FTIR spectra and pattern recognition for discrimination of tea varieties. Int J Biol Macromol 2015;78:439-46.

31. Oliveira RN, Mancini MC, Oliveira FCS de, Passos TM, Quilty B, Thire RM da SM, et al. FTIR analysis and quantification of 
phenols and flavonoids of five commercially available plants extracts used in wound healing. Rev Mater 2016;21:767-79.

32. Nugrahani I, Dillen N. Rapid assay development of diclofenac sodium coated tablet assay using FTIR compared to HPLC method. Int J Appl Pharm 2018;10:43-50.

33. Louer D. Powder X-ray diffraction, applications. In: Lindon JC, Tranter GE, Koppenaal DW. editors. Encyclopedia of Spectroscopy and Spectrometry (Third Edition), Oxford: Academic Press; 2017. p. 723-31.

34. Shaik M, Ali Z, Khan M, Kuniyil M, Assal M, Alkhathlan H, et al. Green synthesis and characterization of palladium nanoparticles using Origanum vulgare $\mathrm{L}$. extract and their catalytic activity. Molecules 2017;22:165.

35. Hernandez C, Ferreira F, Rosa D. X-ray powder diffraction and other analyses of cellulose nanocrystals obtained from corn straw by chemical treatments. Carbohydr Polym 2018;193:39-44.
36. Taani BA, Khanfar M, Alsoud OA. Enhancement of the release of curcumin by the freeze drying technique using inulin and neusilin as carriers. Int J Appl Pharm 2018;10:42-8.

37. Ahmad I. Application of ionic liquid as a green solvent for polyphenolics content extraction of Peperomia pellucida (L) kunth herb. J Young Pharm 2017;9:486-90.

38. Zhang Q, Zhao SH, Chen J, Zhang LW. Application of ionic liquidbased microwave-assisted extraction of flavonoids from Scutellaria baicalensis georgi. J Chromatogr B: Biomed Sci Appl 2015;1002:411-7.

39. Vinatoru M, Mason TJ, Calinescu I. Ultrasonically assisted extraction (UAE) and microwave assisted extraction (MAE) of functional compounds from plant materials. TrAC, Trends Anal Chem 2017;97:159-78. 